\title{
MECHATRONIC APPROACH TO INVENTING A NOVEL KIND OF DEFORMETER
}

\author{
Giuma Ali Shneba, Aleksandar Veg, Dražan Kozak, Aleksandar Sedmak
}

Original scientific paper

Stress and strain measurements on frames and structures are mainly conducted by the use of strain gauges. A measuring chain applied in such measurements usually consists of strain gauges, amplifiers and data acquisition and logging device. The applicability of such instrumentation mainly depends on its sensitivity measuring repeatability, accuracy and noiseless operation. The key point of this paper is harmonization of measuring properties for the newly invented deformeter with the measuring electronics. Much alike a standard modeling of Mechatronic items, a very specific CLD (Close Loop Deformeter) is optimized throughout coupled modeling, bridging analysis of 3D virtual model and real design of laboratory prototype. Virtual experiment was developed to correspond with actual measurements on the test rig. The idea of rectification factor is introduced into concept of $3 \mathrm{D}$ modelling with an innovative CLD research. The focus of the research was kept on the output linearity, measuring range and resolution of the invented deformeter.

Keywords: CAD modelling; close loop deformeter; simulation; strain gauge; stress; transducer

Mehatronički pristup u razvoju novog modela deformetra

Izvorni znanstveni članak

Mjerenje napona i deformacija na različitim konstrukcijama povezano je s primjenom mjernih traka. Mjerni lanac koji se koristi za ovu vrstu mjerenja obično sadrži: mjerne trake, pojačivače i akvizicijsko-memorijske module. Primjenjivost ovakve instrumentacije prvenstveno zavisi od njezine osjetljivosti, mjerne ponovljivosti, točnosti i niske razine šuma. Ključni detalj ovog rada je harmonizacija mjerne karakteristike novorazvijenog deformetra s mjernim svojstvima elektroničke opreme. Vrlo slično klasičnoj metodi modeliranja mehatroničkih jedinica, novopostavljeno rješenje deformetra u obliku zatvorene petlje (CLD) optimizirano je kroz spregnuto modeliranje. Na ovaj način povezano je virtualno ispitivanje 3D modela s ispitivanjem realnog modela u laboratorijskim uvjetima. Program virtualnog eksperimenta razvijen je prema aktivnostima realnog ispitivanja na probnom stolu. Ideja o primjeni rektifikacijskog faktora za preračun naprezanja izmjerenih deformetrom uvedena je i u 3D modeliranje CLD-a. Primarni cilj ovog istraživanja bio je kreiranje novog rješenja deformetra s linearnom mjernom karakteristikom, potrebnim mjernim opsegom i dovoljnom rezolucijom mjerenja.

Ključne riječi: CAD modeliranje; deformetar u obliku zatvorene petlje; mjerna traka; napregnuto stanje; pretvarač; simulacija

\section{Introduction}

Strain gauge is a core sensing element in many types of sensors. Substantially they are used for the stress-strain measurements on different kinds of frames and structures. A vast variety of strain gauges are available either for simple or verse specific measurements. Conventional design of deformeter is a resilient piece of metal flexible enough to detect induced stress.

Sometimes, placement of strain gauge $(\mathrm{SG})$ is difficult, particularly in harsh ambient. Under such circumstances application of the deformeter, instead of a single strain gauge, becomes a real need.

Deformeter is a simple sensing element containing one or more strain gauges. History of strain gauge invention is fractioned in two stages. Early, theoretical considerations were introduced by Charles Wheatstone as long ago as 1843, in his first publication on the bridge circuits [1], as well as by William Thomson $(1824 \div 1905$, Lord Kelvin after 1892) in his publication in 1856 [2]. Later on, in 1930s an applicable technical solution is engineered, based upon an idea of Charles Wheatstone [3].

This paper is inspired by the former work on implementation of 3D modelling in design of omega deformeter [4]. The novelty of our investigation is a breaking through the concept of a Closed Loop Deformeter (CLD) developed by a fundamental Mechatronic approach [5]. That means, the virtual modeling and other techniques are utilized in order to create a satisfactory operation of the CLD, as the integral part of the measuring chain. Several improvements of
CLD were introduced in the optimization process. 3D modeling was aimed not only at pure design, but also at adjustment of its performance under the simulation. The conducted analysis went even a step further, generating a proportional signal on the output contacts of the embedded strain gauge.

\section{The strain gauge operation - in principle}

When a bar receives a tensile force $P$, a certain stress $\sigma$ arises in its body, proportional to the applied force. The cross-section of the bar contracts and the length elongates by $\Delta L$ from the original length $L$.

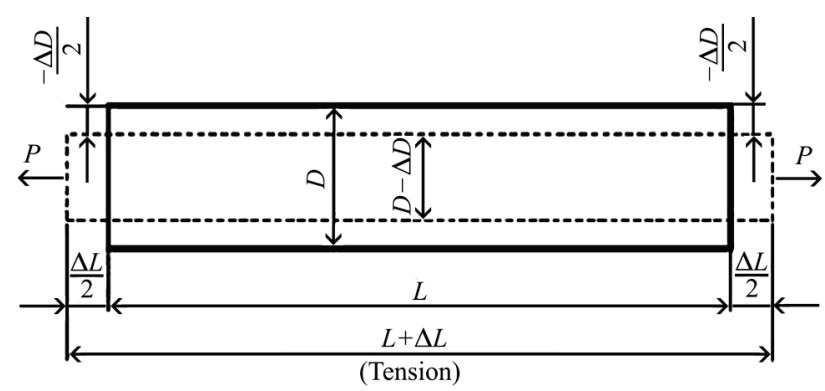

Figure 1 Tension force [6]

The elongation is called a tensile strain and is expressed as follows:

$\varepsilon=\frac{\Delta L}{L}$

Strain $\varepsilon$ is proportional to stress $\sigma$ (Hooke's law): 
$\sigma=E \cdot \varepsilon$

up to elastic limit of the material.

Strain gauge consists of electrical resistance material and when stressed detects a proportional change in resistance

$\varepsilon=\frac{\Delta L}{L}=\frac{\frac{\Delta R}{R}}{K}$

where $R$ is the gauge resistance and $\Delta R$ is the resistance modulation due to strain, and $K$ is the gauge factor.

Normally, a resistance change is a tiny amount and requires a Wheatstone bridge circuit to convert it to a perceivable voltage output.

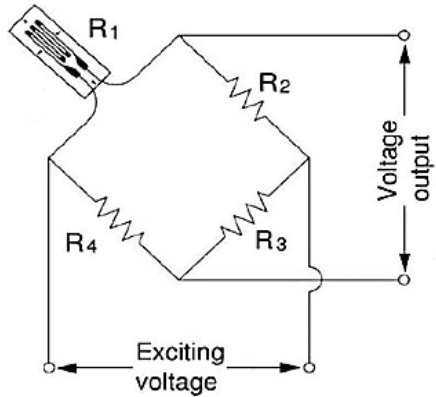

Figure 2 Typical Wheatstone bridge Circuit [4]

$e=\frac{R_{1} R_{3}-R_{2} R_{4}}{\left(R_{1}+R_{2}\right)\left(R_{3}+R_{4}\right)} E$.

Quantity $e$ is the voltage output, $E$ is the excitation voltage, $R_{1}$ is the gauge resistance, and $R_{2} \sim R_{4}$ is fixed resistances.

\section{System description}

Signal conditioning of the strain gauge output Fig. 3 develops over several consecutive blocks Fig. 3. In the first step EMI (Electric Magnetic Impulse) unit suppresses high frequency noise. Then the signal undergoes significant amplification rate (500 times) over an instrument amplifier. The main feature of this component is a low noise and low signal offset. Finally, low pass filter removes high frequency impurities from the signal. The operation of such a block composition is simulated in a dedicated software (Filter Lab and LTS piece) before completing the final design of the electronic circuit. After successful virtual verification, the design process continues with PCB manufacturing and component integration.

Much alike, this Mechatronic approach to measuring device development, an innovative CLD is optimized throughout 3D modelling and virtual testing and engineering.

The core idea is to investigate a substantially different design of, particularly, its behavior when exposed to selected loads. Unlike the standard deformeter shape, CLD has tied up opposed ends with a crossed position. In this concept, linear extension of deformeter ends cause very intensive bending in its central part. Thus the measurement of subtle deformation becomes viable, producing a significant signal. The idea of 3D modeling and its verification in a virtual environment is overtaken from former researches in the same Laboratory [4]. The innovative design of CLD is, however, originally arranged the prototype is also carefully tested, by its applicability, linearity and repeatability.

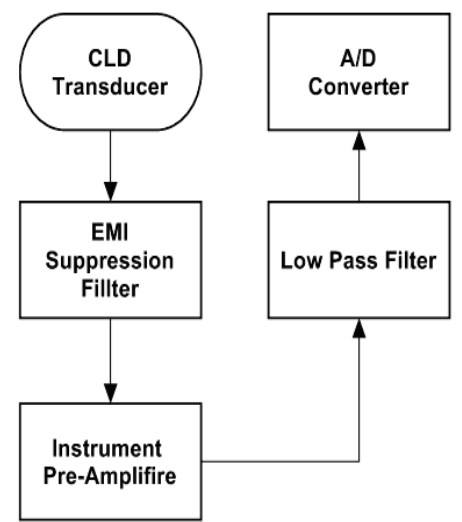

Figure 3 Signal Conditioning Block Compostion

\subsection{Signal conditioning composition}

A fundamental parameter of the strain gauge is its sensitivity to strain. It is expressed as the gauge factor $(G F)$ depicting the ratio of relative change in electrical resistance to the relative change in length (strain):

$G F=\frac{\frac{\Delta R}{R}}{\frac{\Delta L}{L}}=\frac{\frac{\Delta R}{R}}{\varepsilon}$.

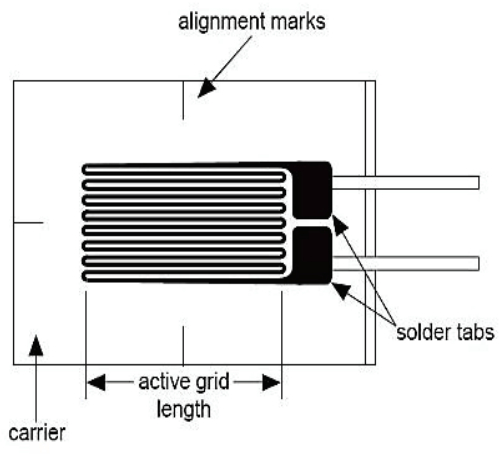

Figure 4 Strain gauge configuration

The Gauge factor for metallic strain gauges is typically around 2 .

Regular strain measurements involve quantities in the range $0 \div 10000\left(\varepsilon \times 10^{-6}\right)$. Therefore, a measurement with the strain gauge requires accurate detection of very small changes in resistance. That change of resistance $\Delta R$ is within overall span $480 \mu \Omega \div 2,4 \Omega$.

\subsection{Bridge excitation}

Strain gauge signal conditioners typically provide a constant voltage source to power the bridge. Most commonly the voltage level is either $3 \mathrm{~V}$ or $10 \mathrm{~V}$. A higher excitation voltage generates a higher voltage 
signal, but also causes larger errors due to self-heating. It is of a crucial importance to have very accurate and stable excitation voltage.

If the strain gauge circuit is located a distance away from the signal conditioner and excitation source, a significant error arises due to resistance in the connecting wires. It is advisable to have all electronic devices in the immediate vicinity.

\subsection{Signal conditioning}

The output signal from the strain gauge and bridges is relatively small. In practice, most strain gauge bridges and strain-based transducers will output less than $10 \mathrm{mV} / \mathrm{V}$ (10 $\mathrm{mV}$ of output per volt of excitation voltage). Therefore, strain gauge signal conditioners usually include amplifiers to boost the signal level to increase measurement resolution and improve signal-to-noise ratio. In order to design a stable, harmonized measuring chain a brief analysis of crucial performance of each stage is conducted. Tab. 1 shows several in consecutive stages in signal generation and conditioning.

The main target in system development is to find out if there are weak points or any misconceptions. Since the
CLD is conceived as a spring deformeter, and its core element is strain gauge, the output from these two is compared, in order to determine degradation extent. Later analysis, applied over 3D model and lab prototype showed that the 4 time signal rating is within acceptable margins. A very poor output signal from CLDmust be significantly amplified and filtered in electronics. Tab. 1 shows obviously that the nature of the signal is preserved, and the filter does no harm in it, while the AD block truly interprets a digital form of the signal. Measuring chain consists of the instrumentation amplifier LTR 1167 which is a high performance component with alow power, and low noise. When processing several signals in parallel a CMOS, 8 channel multiplexer is utilized (MAX 4617). It is popular as a single voltage operated COMS device with low leakage current $(1 \div 10 \mathrm{~mA})$. The filter block is designed with modern components which have no effect on signal stability and intensity. Practically all the noise is removed, while the useful signal is kept untouched. Finally the signal is converted into a numerical record within the A/D converter (LTC 1864). It is a 16 bit, 250 ksps ADC.

Table 1 Overview of signal degradation rate within measuring chain

\begin{tabular}{|c|c|c|c|c|}
\hline \multirow{2}{*}{ Device } & & Range & Resolution & Dynamic Range \\
\hline \multirow{2}{*}{ Strain Gauge } & Induced extension & $0 \div 0,1 \mathrm{~mm}$ & $0,28 \mu \mathrm{m}$ & $1: 300$ \\
\cline { 2 - 5 } & Proportional Strain & $0 \div 10000 \mu \varepsilon$ & $28 \mu \varepsilon$ & $1: 300$ \\
\hline \multirow{2}{*}{ CLD } & Induced extension & $0 \div 10 \mathrm{~mm}$ & $0,1 \mathrm{~mm}$ & $1: 100$ \\
\cline { 2 - 5 } & Proportional Strain & $0 \div 3000 \mu \varepsilon$ & $28 \mu \varepsilon$ & $1: 100$ \\
\hline \multirow{2}{*}{ Pre-Amplifire } & SG to AMP voltage & $\pm 2,4 \mathrm{mV}$ & $0,6 \mu \mathrm{V}$ & $1: 4000$ \\
\hline & AMP/SG output voltage & $\pm 13,25 \mathrm{~V}$ & $0,3 \mathrm{mV}$ & $1: 4000$ \\
\hline & CLD to AMP voltage & $\pm 2,4 \mathrm{mV}$ & $0,6 \mu \mathrm{V}$ & \\
\hline & AMP/CLD output voltage & $\pm 7,95 \mathrm{~V}$ & $0,3 \mathrm{mV}$ & \\
\hline Filter & Useful signal degrade & & No effect & \\
\hline Measuring instrument (ADC) & Input & $\pm 1,25 \mathrm{~V}$ & $0,3 \mathrm{mV}$ & $1: 4000$ \\
\hline
\end{tabular}

\section{CLD 3D modelling}

In order to make a truly operational deformeter some design analysis was carried out. Selected geometric parameters (spring diameter) were varied, to achieve an optimal stiffness. As a boundary acceptable deformeter stiffness it is defined $k_{\mathrm{o}}=9 \mathrm{~N} / \mathrm{mm}$. Fig. 7 shows final shape and size of CLD.

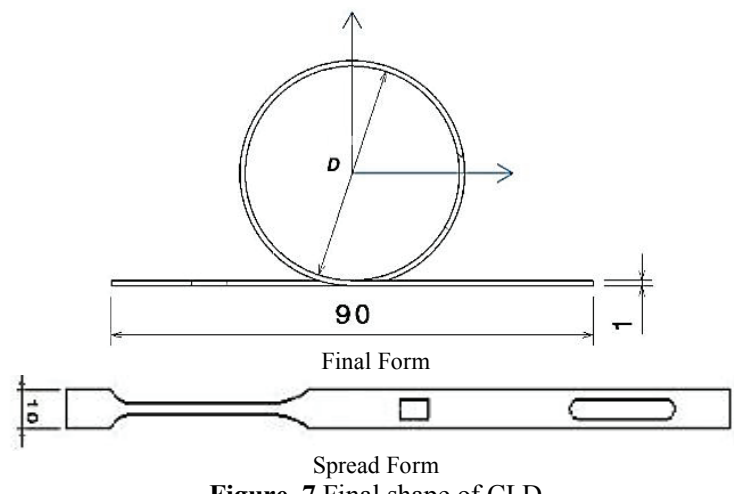

Figure 7 Final shape of CLD

During the CAD modelling quite a range of different diameters has been examined. Each CLD model was equipped with the bonded virtual Strain gauge of $10 \times 5$ $\mathrm{mm}$ dimension. CLDs have been stretched from unloaded, undefined state to the maximal line extension of $10 \mathrm{~mm}$. The margin of the least detectable extension was set to $0,01 \mathrm{~mm}$.

Table 2 Range of CLD diameters

\begin{tabular}{|c|c|}
\hline Spring model & $D(\mathrm{~mm})$ \\
\hline 1 & 30 \\
\hline 2 & 40 \\
\hline 3 & 50 \\
\hline 4 & 60 \\
\hline
\end{tabular}

Numerical analysis was done using the Finite Element Methods. Calculations were done for 4 CLDs different schemes of displacement on CLDs [7] [8]. The most appropriate for calculations of CLD cases of boundary conditions is to fix one end of CLDs and apply displacement at the other end in horizontal direction as shown in Fig. 8. For diagonal tension, the CLD was fixed in direction $-x$-axis and in the $x$-axis direction the displacement was allowed without rotational movement [9].

Any among the selected CLDs 1, 2, 3 and 4 fulfills the required stiffness margin $k_{\mathrm{o}}=9 \mathrm{~N} / \mathrm{mm}$ as shown in 
Fig. 9. The next parameter to verify was maximal stress, achieved in the spring by its full line extension. This parameter was important in order to induce redundant signal on the strain gauge, incorporated in CLD. Diagram, Fig. 10 shows the proportion between introduced line extensions vs. stress created at the point of the bonded strain gauge. Springs are exposed up to the yield strength of the spring steel, $\sigma_{0,2}=1080 \mathrm{MPa}$, or up to the absolute line extension of $10 \mathrm{~mm}$.

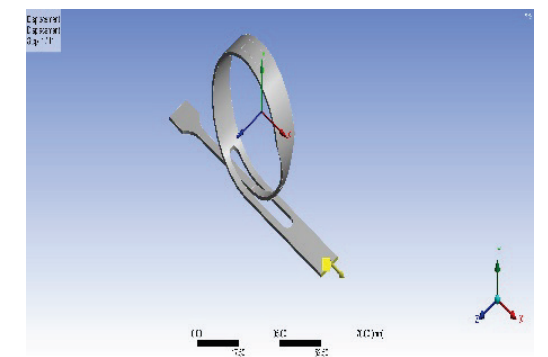

Figure 8 Scheme of displacement on CLD

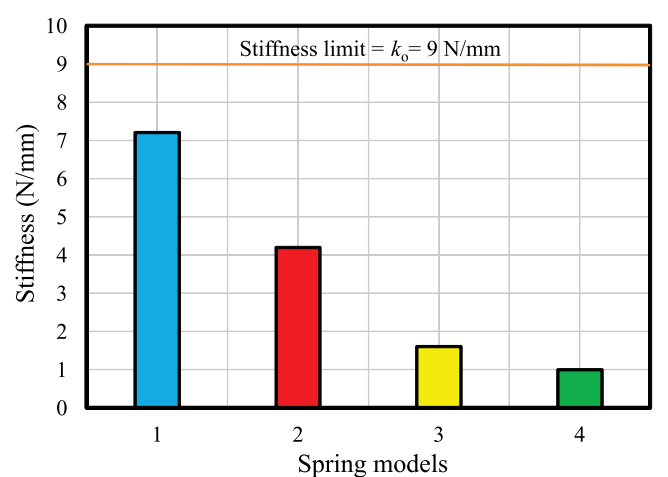

Figure 9 Springs models vs. stiffness diagram

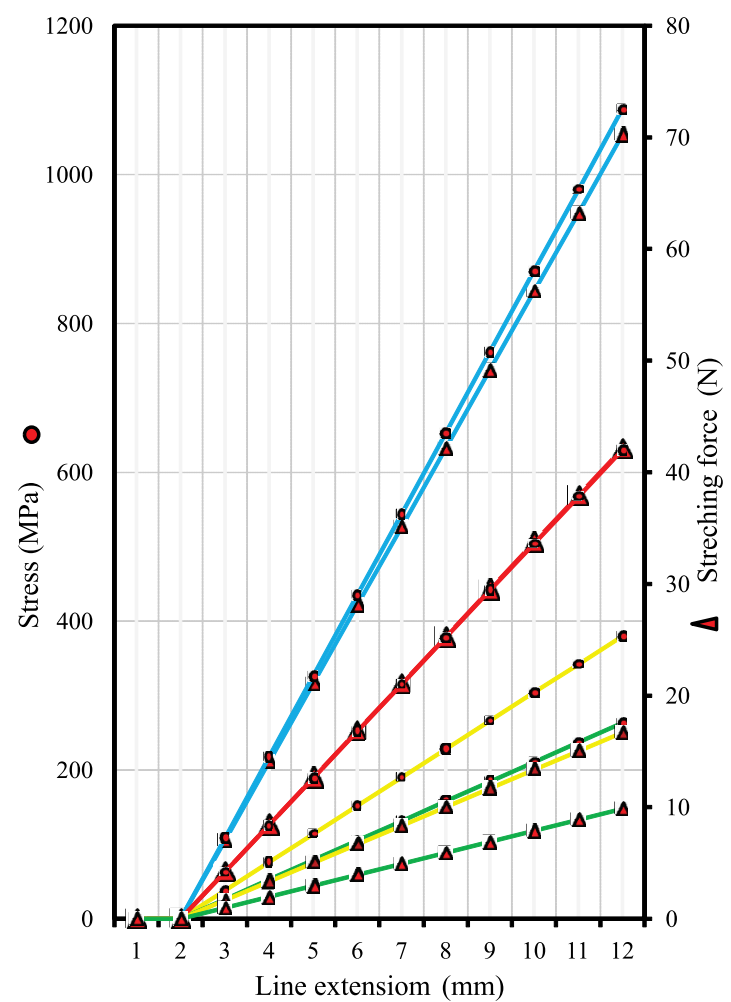

Figure 10 Stress and stretching force vs. line extension

Except the spring no. 1, all other springs are far from the critical margin $\sigma_{\max }<1080 \mathrm{MPa}$ at the rate of $10 \mathrm{~mm}$ extension Fig. 11. If mutually compared, the stresses on the strain gauges of virtual springs are very close, that is, neither spring is prominent by the signal intensity. From an operational point of view, a measurement resolution of $4,064 \times 10^{-6} \mathrm{mV} / \mathrm{V}$, which corresponds to $0,4 \mathrm{MPa}$ strain, depicts an acceptable sensitivity threshold of the strain gauge. Therefore springs no. 3 and 4 do not satisfy this criterion Fig. 12.

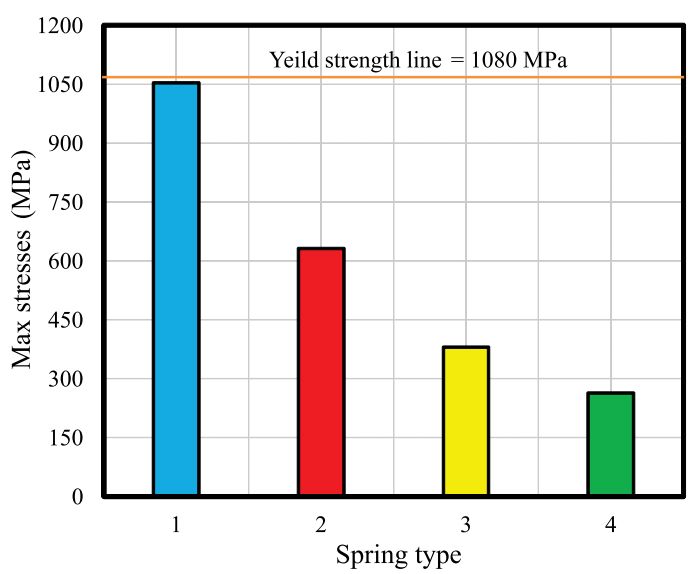

Figure 11 Maximum stress on deformeter diagram

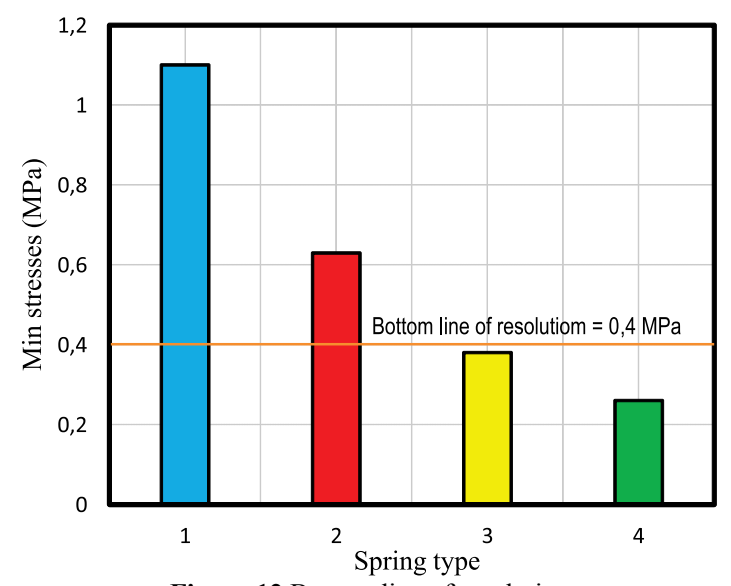

Figure 12 Bottom line of resolution
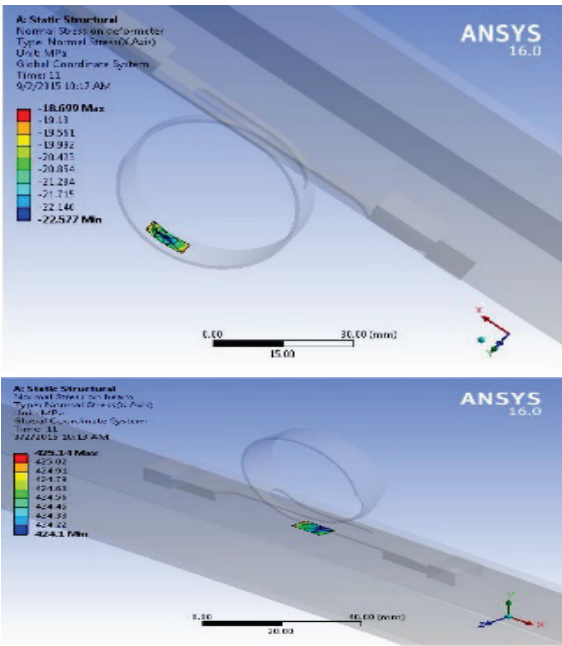

Figure 13 CAD Simulation

Further on, virtual testing in ANSYS [8, 10] was oriented to the spring 2 model, which is both resilient in the sense of measurement sensitivity and strong enough to resist possible overload. 
Table 3 Overview of the stretching force

\begin{tabular}{|c|c|c|c|c|c|c|c|c|c|c|c|c|c|}
\hline & \multirow{2}{*}{\multicolumn{11}{|c|}{ Line extension (mm) }} & \multirow[b]{3}{*}{ Stiffness $(\mathrm{N} / \mathrm{mm})$} \\
\hline & & & & & & & & & & & & & \\
\hline & & 0,01 & 1 & 2 & 3 & 4 & 5 & 6 & 7 & 8 & 9 & 10 & \\
\hline \multirow{4}{*}{ 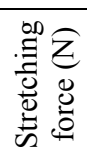 } & Spring 1 & 0,07 & 7,26 & 14,51 & 21,76 & 29,02 & 36,27 & 43,53 & 50,78 & 58,04 & 65,3 & 72,55 & 7,2 \\
\hline & Spring 2 & 0,04 & 4,20 & 8,40 & 12,60 & 16,80 & 21,00 & 25,20 & 29,40 & 33,60 & 37,81 & 42,01 & 4,2 \\
\hline & Spring 3 & 0,20 & 1,67 & 3,34 & 5,01 & 6,68 & 8,35 & 10,02 & 11,69 & 13,36 & 15,03 & 16,7 & 1,6 \\
\hline & Spring 4 & 0,01 & 0,98 & 1,97 & 2,95 & 3,94 & 4,93 & 5,91 & 6,90 & 7,87 & 8,85 & 9,85 & 1,0 \\
\hline
\end{tabular}

Table 4 Stress vs line extension values

\begin{tabular}{|c|c|c|c|c|c|c|c|c|c|c|c|c|}
\hline & \multicolumn{11}{|c|}{ Line extension (mm) } \\
\hline & & 0,01 & 1 & 2 & 3 & 4 & 5 & 6 & 7 & 8 & 9 & 10 \\
\hline \multirow{4}{*}{ 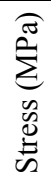 } & Spring 1 & 1,1 & 105,37 & 210,74 & 316,1 & 421,47 & 526,83 & 632,19 & 737,55 & 842,9 & 948,26 & 1053,6 \\
\hline & Spring 2 & 0,63 & 63,18 & 126,36 & 189,54 & 252,71 & 315,88 & 379,04 & 442,2 & 505,36 & 568,51 & 631,66 \\
\hline & Spring 3 & 0,38 & 38,00 & 76,01 & 114,01 & 152,01 & 190,01 & 228,01 & 266 & 304 & 342 & 379,99 \\
\hline & Spring 4 & 0,26 & 26,34 & 52,67 & 79,00 & 105,34 & 131,67 & 158 & 184,32 & 210,65 & 236,97 & 263,29 \\
\hline
\end{tabular}

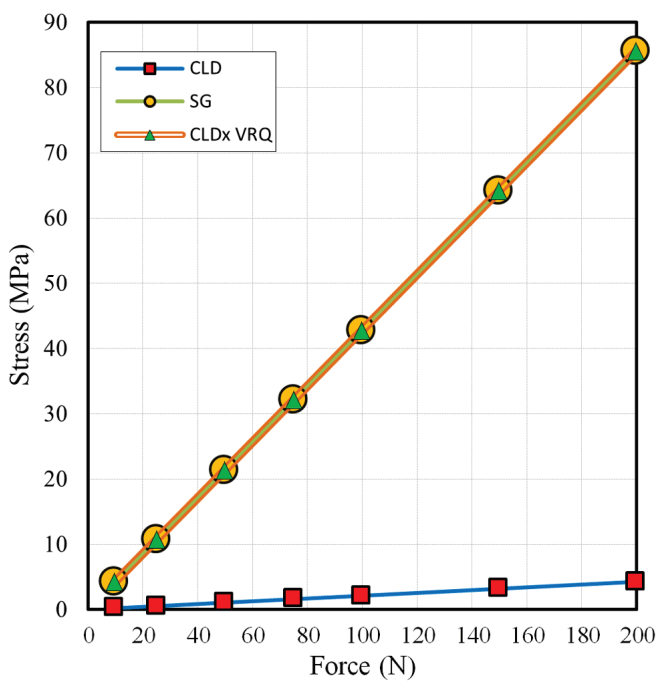

Figure 14 Stress results by force applied

Virtual experiment is defined in such a manner that the CLD is placed on a simple beam, (cross-section square profiles $30 \times 30 \mathrm{~mm}$, with $2 \mathrm{~mm}$ wall thickness) of a total length $L=4 \mathrm{~m}$, between supporting points. In the mid-span of the square beam a virtual Strain gauge is fixed and above it a CLD. This set was loaded by a consecutively increasing force ranging from 10 to $200 \mathrm{~N}$.

Fig. 14 presents the results, read from the virtual strain gauge on the beam (olive green line/ orange circle) and the virtual strain gauge on the CLD (blue line/ red square). At this point we are going to define a coefficient, which determines the relation between two graph lines (red and blue), Fig. 14. That is actually a kind of Virtual Rectification Quotient (VRQ). Over the range of applied load simulation on the spring no. 2, average value is equal to $V R Q=22,7$. Yellow line (green triangles) in the diagram Fig. 14 indicates the induced stress, rectified by $V R Q$. This virtual study proves a perfect compliance between originally measured stresses on the beam and ones detected by CLD.

\section{$5 \quad$ Lab measurment}

Having the virtual examination finished, a real CLD design is finalized in CATIA [11] and the prototype is manufactured, after spring 2 shape. Actual shape and dimension of the CLD is shown in Fig. 15.
CLD item is made of a spring steel. In order to simplify its fixing to the structure, at each end of CLD there is a mounting foot. For the Lab testing, a simple beam, of the same form as in a virtual 3D modeling is used. It is a steel made square profile, cross-section $(30 \times 30 \mathrm{~mm} /$ wall thickness $2 \mathrm{~mm})$, length $L=4 \mathrm{~m}$.
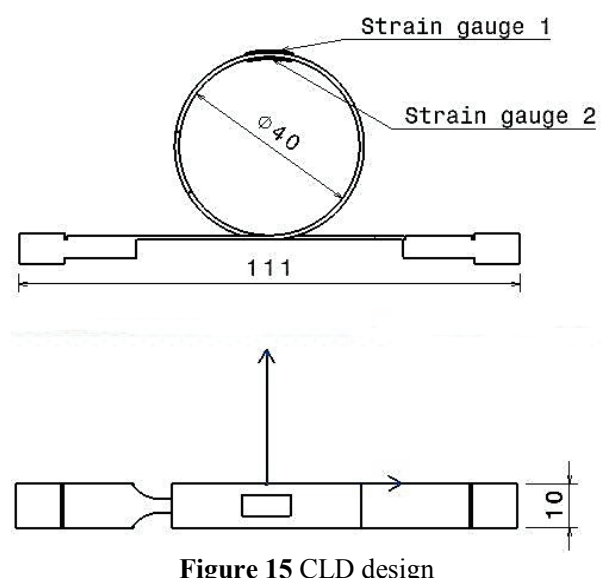

Figure 15 CLD design

In the mid-span of the beam, a strain gauge pair is mounted (one active and one temp. Compensating strain gauge), configured as a half-bridge. Right above the active strain gauge, a CLD is fixed to the steel beam Fig. 16.

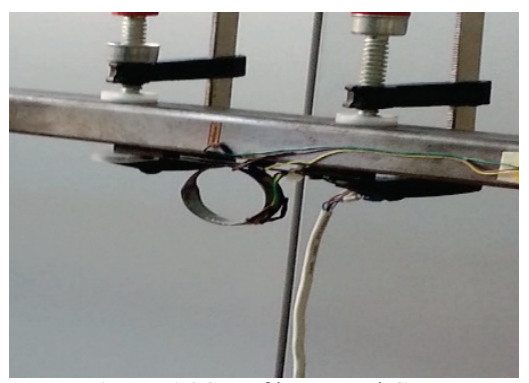

Figure 16 Set of beam and CLD

Two active strain gauges are glued to the CLD, one on the outer and one on the inner side of the loop. For the stress calculation on CLD, the following formula is applied [12]:

$\varepsilon=\frac{1}{B} \cdot \frac{4}{K} \cdot \frac{U_{\mathrm{A}}}{U_{\mathrm{E}}}$ 
$K$ is the gauge factor $=2,12, B$ is the bridge factor, $U_{\mathrm{A}}$ is the bridge output voltage, and $U_{\mathrm{E}}$ is the bridge input voltage.

The bridge factor $=2$ for configuration with two active strain gauges. For the data acquisition a dedicated device, DynaLog instrument, RoTech (www.rotech.rs) make, was used. The device is a multi channel Data Logger, equipped with 16 bit resolution ADC Fig. 17.
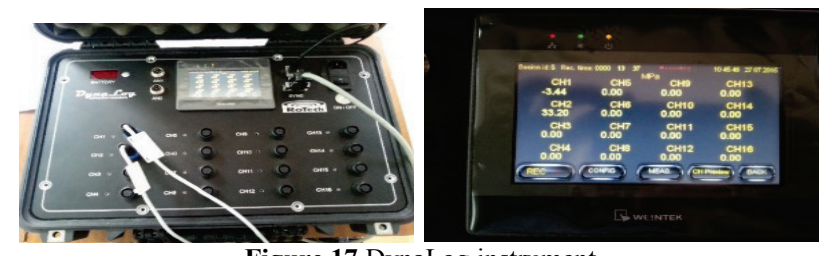

Figure 17 DynaLog instrument

Lab test is conceived in the same manner as the virtual experiment. The steel beam is exposed to bending, induced by adding on lumped masses. As well a random load is applied to justify compliance between direct and CLD measurement Fig. 18.
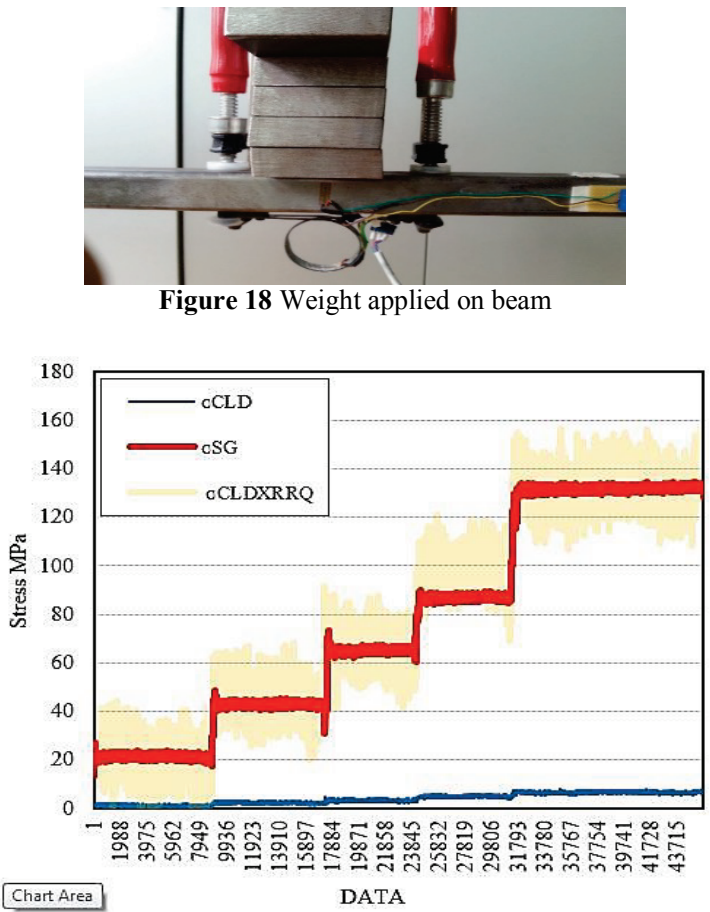

Figure 19 Comparison of SG and CLD Measurement

After a series of repeated tests, it was determined experimentally that the Real Rectification Quotient $(R R Q)$ of CLD is $R R Q=20,36$. The outcome of the measurement is shown in the diagram Fig. 19. Blue and red line present raw signals collected from the transducers. Light orange line depicts a rectified $(R R Q=$ 20,36) output from CLD. Set of sampling points (range 1 $\div 4000$ ), is generated by a stepping load. Correlation function was applied for the justification of signal compliance. The formula is:

$$
\operatorname{Correl}(x, y)=\frac{\sum(x-\bar{x})(y-\bar{y})}{\sqrt{\sum(x-\bar{x})^{2} \sum(y-\bar{y})^{2}}},
$$

$x=\sigma_{\mathrm{SG}}-$ stress measured directly on the beam.

$y=\sigma_{\mathrm{CLD}} \times R R Q-$ stress measured by CLD.

$\bar{x}=\sum_{i=1}^{n} \frac{x_{i}}{n}-$ Average value of the $\sigma_{\mathrm{SG}}$.

$\bar{y}=\sum_{i=1}^{n} \frac{y_{i}}{n}-$ Average value of the $\sigma_{\mathrm{CLD}} \times R R Q$.

The degree of the correlation is:

Correl $\left[\sigma_{\mathrm{SG}} ; \sigma_{\mathrm{CLD}} \times R R Q\right]=0,99$.

\section{Result analysis}

Lab measurements explicitly proved a linear output characteristic of CLD. It was also indicated in 3D modelling. Next is a functional compliance between stress and dilatation in CLD. The stress on the original surface of the beam is related by a constant factor to the one detected by CLD. This relation is depicted by a spring coefficient. Its value for the CLD spring 2 is $V R Q=22,7$. In order to get the same order stress value after laboratory tests, it is necessary to convert detected voltage with the instrument into a physical value of the stress. Signal output, both from the strain gauge and CLD has been collected together.

Actual dilatation $\varepsilon$, is calculated applying Eq. (6). For the Wheatstone half bridge, with one active and one temp. Compensating strain gauge, bridge factor is $B=1$. This kind of configuration on a steel beam, yields the equation:

$\varepsilon_{\mathrm{SG}}=\frac{4}{k} \cdot \frac{U_{\mathrm{ASG}}}{U_{\mathrm{ESG}}}$

Unlike, on CLD a half bridge comprises two active strain gauges, so the Wheatstone bridge factor is $B=2$ [12]. The corresponding dilatation then is:

$\varepsilon_{\mathrm{CLD}}=\frac{4}{2 k} \cdot \frac{U_{\mathrm{ACLD}}}{U_{\mathrm{ECLD}}}$.

According to the Hook's law, stress is directly proportional to the dilatation so it makes no difference whichever parameter is used for the calculation of $R R Q$ [13].

$R R Q=\sum_{i=1}^{n} \frac{\frac{\varepsilon_{\mathrm{SG}}}{\varepsilon_{\mathrm{CLD}}}}{n}$

$R R Q$ is derived as a mathematical average value from all collected points, considering just the points where either $\varepsilon_{\mathrm{SG}}$ or $\varepsilon_{\mathrm{CLD}}$ is greater than 0,001 :

$\varepsilon_{\mathrm{SG}}<0,001 \wedge \varepsilon_{\mathrm{CLD}}>0,001$

Charts in Fig. 20 show the distribution of the $R R Q$ around an average value. 
Red line represents the average coefficient value $R R Q$ $=20,36$, while the blue dots are varying around, as the ratio of $\sigma_{\mathrm{SG}}$ and $\sigma_{\mathrm{CLD}}$ fluctuates in Lab test.

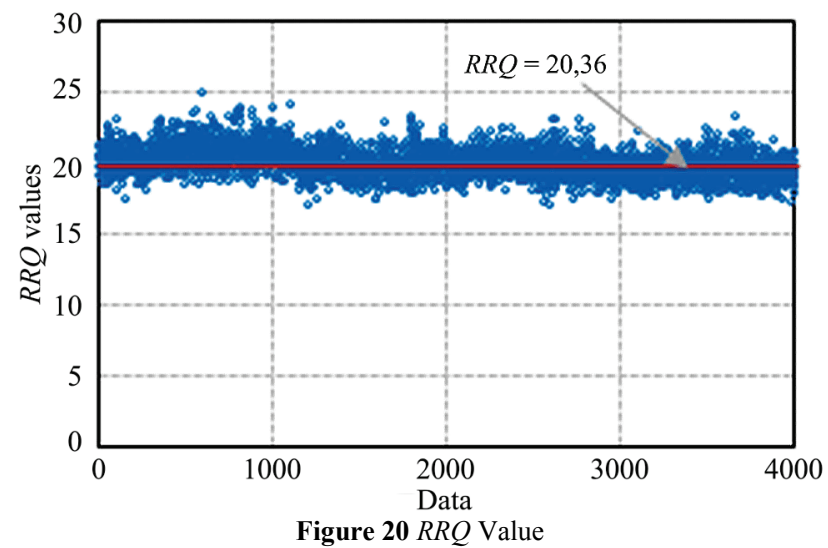

\section{Conclusion}

An original idea of implementing 3D modelling in deformeter development [4], already known and introduced into practice, is much improved with our Mechatronic approach to the substantial harmonization of the deformeter output with an overall measuring performance. A novel kind of deformeter, called CLD is settled as a concept. On the other hand its conceptual design could not guarantee successful operation.

Therefore a virtual measuring configuration is conceived and within it a true analysis is performed.

Having an outline of the complete system the appropriate virtual model of CLD is developed. Further virtual examination is conducted by ANSYS Software in order to select an optimal model of CLD. During laboratory testing, it was revealed that RRQ is slightly different from the VRQ. It is assumed that the detected difference is a result of imperfection in either modelling or selected material properties. However, by implementing RRQ in laboratory tests, almost perfect, $99 \%$ match is achieved between stress value from the original strain gauge and CLD. Final conclusion would be that CLD is a type of sensor that could substitute strain gauge wherever arise difficulties in attaching it, as well when intended operation is in a harsh area with extensive deflections. Further investigations of CLD performance will be oriented to the site testing on different structures and more complex loadings [14].

\section{References}

[1] Charles, W. An Account of several new Instruments and Processes for deterring the Constants of a Voltaic Circuit. Philosophical Transactions Royal Society of London, 1843.

[2] William, T. ON the Electro-dynamic Qualities Metals. Philosophical Transactions Royal Society of London, 1856.

[3] Hoffmann, K. An Introduction to Stress Analysis and Transducer Design using Strain Gauge. HBM, Germany, 2012.

[4] Regodic, M.; Sinikovic, G.; Veg, E.; Veg, A.; Andrejevic, R.; Gubeljak, N. Development of Omega Deformeter. // $14^{\text {th }}$ World Congress in Mechanism and Machine Science, Taipei, 2015 DOI: 10.6567/IFToMM.14TH.WC.OS13.025
[5] David, G. Alicatore.; Michael, B. Histand. Introduction to Mechatronics and Measurement Systems. McGraw-Hill, New York, 2001.

[6] TML, Strain Gauge-type Transducer, Tokyo Sokki Kenkyujo Co, Ltd, TML Pam E101S.http://www.tml.jp/e/download/catalog/STRAIN_GA UGES (23.09.2015)

[7] Maślak, P.; Smolnicki, T.; Pietrusiak, D. Strain Gauges Measurements and FEM Analysis of Elements of Open Cast Mining Machines. // Tehnicki vjesnik-Technical Gazette. 20, 4(2013), pp. 655-658.

[8] Huang Lee, H. Finite Element Simulations with ANSYS Workbench 16. SDC, USA, 2015.

[9] Kaygin, B.; Yorur, H.; Uysal, B. Simulating Strength Behaviors of Corner Joints of Wood Constructions by Using Finite Element Method. // Tehnicki vjesnikTechnical Gazette. 23, 5(2016), pp. 133-140. DOI: 10.5552/drind.2016.1503

[10] Nakasone, N.; Yoshimoto, S. Engineering Analysis with ANSYS software, BH, USA, 2006.

[11] Tickoo, S.; Sethi, G. S. CATIA V15R21 for Engineers and Designers. Dreamtech Press, USA, 2012.

[12] Hoffmann, K. Applying the Wheatstone Bridge Circuit. HBM, Germany, http://www.hbm.com/en/3193/tips-andtricks-applying-the-wheatstone-bridge-circuit/ (14.03.2015)

[13] Soloman, S. Sensor Handbook, $2^{\text {nd }}$ Ed. United Sate of America: Mc Graw Hill, 2010.

[14] Rally, M. J. Bridge management. $1^{\text {st }}$ Ed. Oxford: Butterworth-Heinemann, 2001.

[15] TML, Precise \& Flexible Strain Gauge Tokyo Sokki Kenkyujo Co, Ltd, TML Pam E-701C. http://www.tml.jp/e/product/strain gauge/ (27.01.2015)

[16] TML, Strain Gauge-type Civil Engineering Transducers, Tokyo Sokki Kenkyujo Co, Ltd, TML Pam E720S.http://www.tml.jp/e/product/transducers/general/displ acement/index.html (24.02.2015)

\section{Authors' addresses}

Giuma Ali Shneba, PhD student

Mechanical Engineering Faculty,

University of Belgrade,

Kraljice Marije 16, 11000 Belgrade, Serbia

E-mail: giumashneba@yahoo.com

Aleksandar Veg, Prof. Dr

Mechanical Engineering Faculty,

University of Belgrade,

Kraljice Marije 16, 11000 Belgrade, Serbia

E-mail: Aleksandar.veg@rotech.rs

Dražan Kozak, Prof. dr. sc.

Mechanical Engineering Faculty in Slavonski Brod,

University of J. J. Strossmayera in Osijek,

Trg Ivane Brlić-Mažuranić 2,

35000 Slavonski Brod, Croatia

E-mail: dkozak@sfsb.hr

Aleksandar Sedmak, Prof. Dr

Mechanical Engineering Faculty,

University of Belgrade

Kraljice Marije 16, 11000 Belgrade, Serbia

E-mail: asedmak@mas.bg.ac.rs 